Check for updates

Cite this: RSC Adv., 2018, 8, 35813

Received 31st August 2018

Accepted 15th October 2018

DOI: $10.1039 / c 8 \mathrm{ra07260d}$

rsc.li/rsc-advances

\section{Influence of citrate on phase transformation and photoluminescence properties in $\mathrm{LaPO}_{4}$ and $\mathrm{LaPO}_{4}:$ Eu†}

\author{
An-Ping Wu, ${ }^{a} \mathrm{He} \mathrm{Bai}{ }^{a}$ Jin-Rong Bao, (D) *a Kui-Suo Yang, ${ }^{a} \mathrm{Li}-\mathrm{Na}$ Feng, ${ }^{a}$ \\ Yang-Yang Ma, ${ }^{a}$ Yan Qiao, ${ }^{a}$ Wen-Xian Li, ${ }^{a}$ Ying Liu (iD a and Xiao-Wei Zhu*b
}

\begin{abstract}
The hexagonal and monoclinic phase $\mathrm{LaPO}_{4}$ and $\mathrm{LaPO}_{4}: \mathrm{Eu}$ nanostructures have been controllably synthesized by a citrate-induced hydrothermal process at $100{ }^{\circ} \mathrm{C}$. The crystal growth of $\mathrm{LaPO}_{4}$ nanostructures was investigated, and the phase transformation of nanostructured $\mathrm{LaPO}_{4}$ was systematically studied by varying the citrate concentration, $\mathrm{pH}$ value and reaction temperature. When $0.8 \mathrm{mmol}$ of citrate was added into the reaction system, the hexagonal phase $\mathrm{LaPO}_{4}$ transformed into the monoclinic phase. High concentrations of citrate would lead to the formation of hexagonal phase $\mathrm{LaPO}_{4}$. The photoluminescence properties of the monoclinic phase $\mathrm{LaPO}_{4}$ :Eu prepared using a citrateinduced process demonstrate that the electric dipole transition $\left({ }^{5} D_{0} \rightarrow{ }^{7} F_{2}\right)$ is stronger than the magnetic dipole transition $\left({ }^{5} \mathrm{D}_{0} \rightarrow{ }^{7} \mathrm{~F}_{1}\right)$, which indicated that $\mathrm{Eu}^{3+}$ is in a site with no inversion center. The strongest emission peak of hexagonal phase $\mathrm{LaPO}_{4}$ :Eu comes from ${ }^{5} \mathrm{D}_{0} \rightarrow{ }^{7} \mathrm{~F}_{1}$. Furthermore, the citrate-induced hexagonal phase $\mathrm{LaPO}_{4}$ : $\mathrm{Eu}$ has a stronger emission intensity than the hexagonal phase $\mathrm{LaPO}_{4}$ :Eu prepared not using a citrate-induced process.
\end{abstract}

\section{Introduction}

In recent years, the rare earth orthophosphates have received much attention, due to their electronic, optical, and chemical characteristics. ${ }^{1}$ For example, they are used as phosphors, light sources, high-performance luminescent devices, field-effect transistors, solar cells, and biomedical labels. ${ }^{2-7}$ Rare earth orthophosphates are rich in polymorphs, which usually include monazite (monoclinic), xenotime (tetragonal), rhabdophane (hexagonal), weinschenkite (monoclinic). ${ }^{8}$ Phase transformation is very common in these polymorphs. The hexagonal phase rare earth orthophosphates are obtained at low temperature, and can transform into the monoclinic phase at high temperature. ${ }^{9}$ As important photoluminescent host materials, the hexagonal structured lanthanum orthophosphates are usually prepared from a sol-gel $\operatorname{method}^{\mathbf{1 0}}$ and hydrothermal method ${ }^{11}$ at lowtemperature, while the monoclinic phase lanthanum orthophosphates can be prepared at high temperature. For example, the monoclinic phase $\mathrm{LaPO}_{4}$ could be synthesized through hydrothermal reaction at $180{ }^{\circ} \mathrm{C}_{;}{ }^{12}$ the monoclinic phase $\mathrm{LaPO}_{4}$ :Er was obtained via solid state reaction at $1200{ }^{\circ} \mathrm{C} ;{ }^{13}$ and the monoclinic

${ }^{a}$ School of Chemistry and Chemical Engineering, Inner Mongolia University, Hohhot 010021, China. E-mail: jinrongbao@imu.edu.cn; Tel: +86-0471-4992981

${ }^{b}$ College of Pharmacology, Inner Mongolia Medical University, Hohhot 010059, China. E-mail: zxwtxwd@sina.com

† Electronic supplementary information (ESI) available. See DOI: 10.1039/c8ra07260d phase $\mathrm{LaPO}_{4}$ :Eu could also be formed in high boiling coordinating solvents at $200{ }^{\circ} \mathrm{C}^{\mathbf{1 4}}$ Recently, the low temperature synthesis method of the monoclinic phase $\mathrm{REPO}_{4}$ has received much attention. Several pressure-induced phase transformations of $\mathrm{ABO}_{4}(\mathrm{~A}=\mathrm{Ba}, \mathrm{Ca}, \mathrm{Sr}, \mathrm{Tb}, \mathrm{Dy} ; \mathrm{B}=\mathrm{Cr}, \mathrm{W}, \mathrm{P})$ compounds have been discovered. ${ }^{15-18}$ In particular, the organic ligand-induced phase transformation of $\mathrm{REPO}_{4}$ compounds at low temperature has been studied. Yan et al. ${ }^{19}$ reported an ethylenediaminetetraacetic acid (EDTA)-mediated hydrothermal route to synthesize different phase cerium orthovanadate $\left(\mathrm{CeVO}_{4}\right)$ microcrystals. In our previous study, we found that nanostructured $\mathrm{CePO}_{4}$ : $\mathrm{Tb}$ with hexagonal and monoclinic phases could be controllably synthesized through a hydrothermal route at $150{ }^{\circ} \mathrm{C}$ by simply varying the reactant $\mathrm{C}_{2} \mathrm{O}_{4}{ }^{2-} / \mathrm{Ce}$ molar ratio. ${ }^{20}$ Nuria et $a l^{21}$ have synthesized monazite $\mathrm{LnPO}_{4}(\mathrm{Ln}=\mathrm{La}, \mathrm{Ce})$ and $\mathrm{LaPO}_{4}: \mathrm{Ln}(\mathrm{Ln}=\mathrm{Eu}, \mathrm{Ce}, \mathrm{Ce}+\mathrm{Tb})$ through the controlled release of $\mathrm{La}^{3+}$ cations from lanthanide-citrate complexes using ethylene glycol (EG) as solvent. Among a variety of organic additives, trisodium citrate $\left(\mathrm{Cit}^{3-}\right)$ is one of the most common and important organic molecules. ${ }^{22,23}$ Actually, citrate is often used as a structure-directing agent to control the nucleation, growth and alignment of $\mathrm{REPO}_{4}$ crystals. ${ }^{24,25}$ In order to achieve the phase transformation of $\mathrm{REPO}_{4}$ compounds at low temperature, the organic ligand-induce might be a feasible method.

In this paper, we developed an effective method to synthesis the $\mathrm{LaPO}_{4}$ and $\mathrm{LaPO}_{4}$ :Eu with hexagonal phase and monoclinic phase by the citrate-induced hydrothermal process at low temperature. Furthermore, the function of citrate-induce on the phase transformation of $\mathrm{LaPO}_{4}$ was systematically investigated. 
It is interesting to note that monoclinic phase $\mathrm{LaPO}_{4}$ nanoparticles grow better if $0.8 \mathrm{mmol}$ of citrate is used. Similarly, the monoclinic phase and hexagonal phase $\mathrm{CePO}_{4}$ can be obtained, respectively. The monoclinic phase $\mathrm{CePO}_{4}$ can be obtained while citrate concentration increased to $1.2 \mathrm{mmol}$. High concentration of citrate would result in the formation of hexagonal phase rare earth orthophosphates. We also discussed the effect of high concentration citrate on the phase transformation, and the photoluminescence properties of the $\mathrm{LaPO}_{4}: \mathrm{Eu}$ with different phase and size.

\section{Experimental}

\subsection{Material and reagents}

All chemicals were of analytical grade and were used as received without further purification. $\mathrm{H}_{3} \mathrm{PO}_{4}$ (A.R.), $\mathrm{HNO}_{3}$ (A.R.), $\mathrm{NH}_{3} \cdot \mathrm{H}_{2} \mathrm{O}$ (A.R.), $\mathrm{La}\left(\mathrm{NO}_{3}\right)_{3} \cdot 6 \mathrm{H}_{2} \mathrm{O}$ (A.R.), sodium citrate dihydrate, $\mathrm{Ce}\left(\mathrm{NO}_{3}\right)_{3} \cdot 6 \mathrm{H}_{2} \mathrm{O}$ (A.R.) and $\mathrm{Eu}_{2} \mathrm{O}_{3}$ (purity > 99.99\%) were all supplied by Sinopharm Chemical Reagent Limited Corporation. The europium nitrate was prepared by dissolving $\mathrm{Eu}_{2} \mathrm{O}_{3}$ in $10 \%$ nitric acid, and then evaporated and dried in vacuum.

\subsection{Synthesis}

In a typical procedure using citrate as ligand, 0.0-3.0 $\mathrm{mmol}$ sodium citrate dihydrate was added to $0.1 \mathrm{~mol} \mathrm{~L}^{-1}$ of $\mathrm{La}\left(\mathrm{NO}_{3}\right)_{3}$ solution while kept under stirring. The solution turned turbid due to the formation of lanthanum citrate complex under vigorous stirring for $20 \mathrm{~min}$. Subsequently, $0.1 \mathrm{~mol} \mathrm{~L}{ }^{-1} \mathrm{H}_{3} \mathrm{PO}_{4}$ was added slowly while kept under stirring at $10 \mathrm{~min}$. The obtained turbid solution was transferred into a stainless steel autoclave with an inner Teflon vessel (volume, $50 \mathrm{~mL}$ ). It was sealed and maintained at $100{ }^{\circ} \mathrm{C}$ for $12 \mathrm{~h}$. After cooling to room temperature, the precipitation was separated by centrifugation, washed with deionized water and ethanol absolute three times, and finally dried at $60{ }^{\circ} \mathrm{C}$ for $8 \mathrm{~h}$. In this way, the $\mathrm{La}_{0.95} \mathrm{PO}_{4}$ :- $^{-}$ $\mathrm{Eu}_{0.05}$ and $\mathrm{CePO}_{4}$ were synthesized.

\subsection{Characterization}

The size and morphology of the products were characterized by scanning electronic microscopy (SEM, Hitachi S-4800, Japan) and transmission electron microscopy (TEM, FEI Tecnai F20, USA). XRD patterns were measured by a $21 \mathrm{~kW}$ extra power X-ray diffractometer (Model M21XVHF22, MAC science Co. Ltd., Japan) using $\mathrm{Cu} \mathrm{K} \alpha$ radiation $(k=0.1541 \mathrm{~nm})$ over a $2 \theta$ range of $10-60^{\circ}$ at room temperature. The photoluminescence spectra of powders were recorded on FL Spectrophotometer (FLS-980) with the slit width of $1.0 \mathrm{~nm}$ at room temperature.

\section{Result and discussion}

\subsection{Structure of $\mathrm{LaPO}_{4}$ and $\mathrm{CePO}_{4}$}

In this study, the different crystalline phases of $\mathrm{LaPO}_{4}$ were prepared using different concentration of citrate as ligand. The phase structures of the products were identified by X-ray diffraction (Fig. 1). The typical XRD pattern of the product prepared with $0.8 \mathrm{mmol}$ citrate is shown in Fig. 1a, all

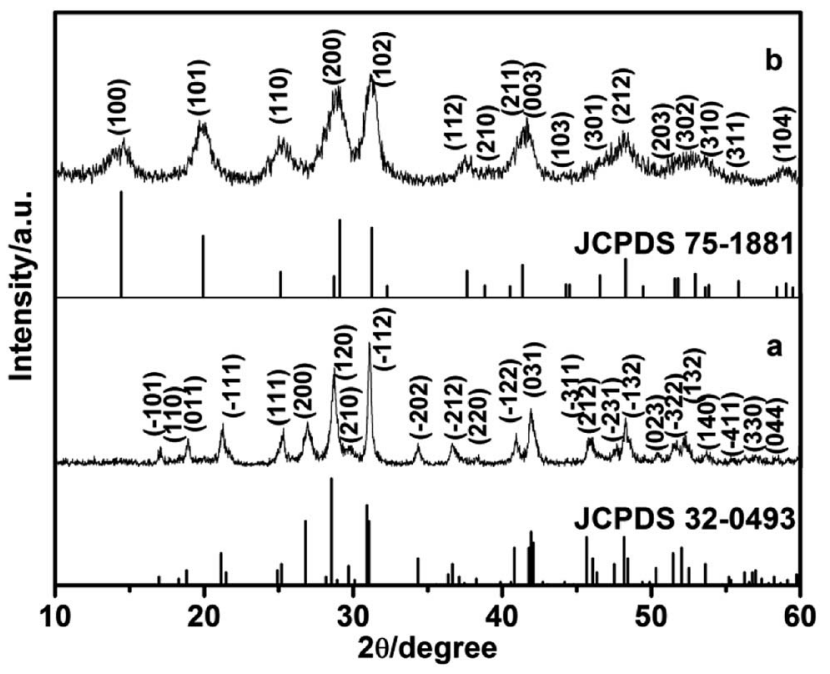

Fig. 1 XRD patterns of $\mathrm{LaPO}_{4}$ nanostructures prepared with citrateinduced $(a)$ the monoclinic phase and $(b)$ the hexagonal phase.

diffraction peaks agree well with monoclinic phase $\mathrm{LaPO}_{4}$ (JCPDS 32-0493). The diffraction peaks were very strong and sharp, indicating that the sample has a good crystallinity. While citrate concentration is $3.0 \mathrm{mmol}$, all the peaks can be indexed to the hexagonal phase $\mathrm{LaPO}_{4}$, which was in good agreement with the JCPDS 75-1881 (Fig. 1b). Therefore, the phase transformation of $\mathrm{LaPO}_{4}$ can be controlled by varying citrate concentration.

TEM images of as-synthesized hexagonal and monoclinic phase products were shown in Fig. 2. Fig. 2a presents the TEM images of the product synthesized with $0.8 \mathrm{mmol}$ citrate. The as-synthesized monoclinic phase $\mathrm{LaPO}_{4}$ was composed of nanoparticles, its average grain size was about $40 \mathrm{~nm}$ by using
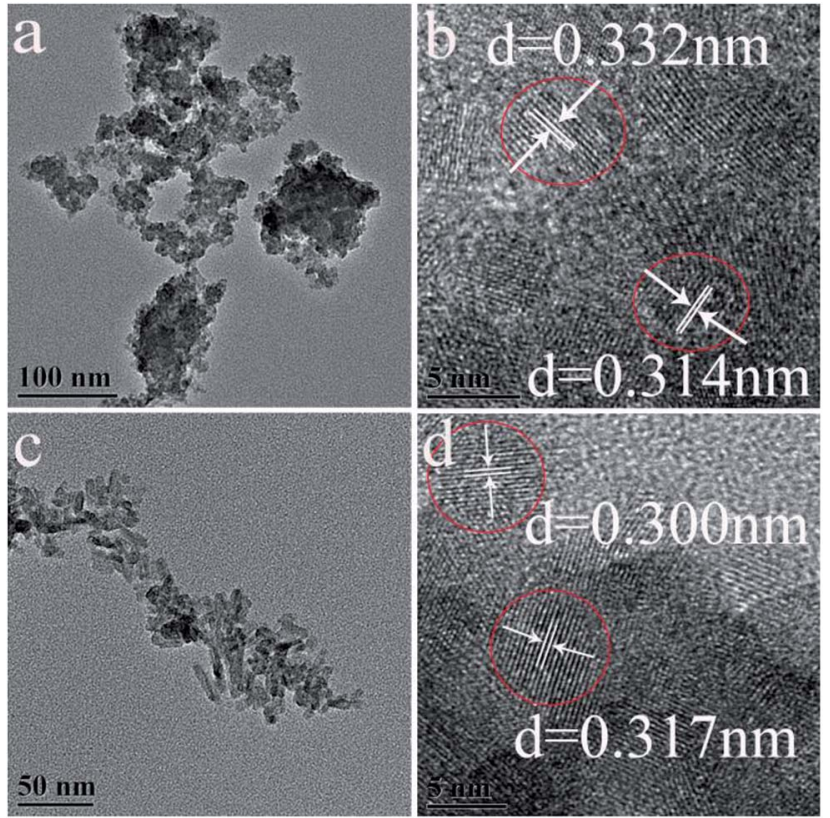

Fig. 2 TEM images of $\mathrm{LaPO}_{4}$ nanostructures prepared with citrateinduced (a) the monoclinic phase, (b) HRTEM image of the monoclinic phase, (c) the hexagonal phase, (d) HRTEM image of the hexagonal phase. 
the formula of Debye-Scherrer to calculate. A high-resolution TEM image (Fig. 2b) showed that the spacing of the sample between two adjacent horizontal and vertical lattice planes is $3.32 \AA$ and $3.14 \AA$ (Fig. 2b), close to the $d_{200}$ (3.326 $\mathrm{\AA}$ ) and $d_{120}$ $(3.127 \AA)$, respectively. When citrate concentration was $3.0 \mathrm{mmol}$, the as-obtained hexagonal phase product has rodlike morphology, and its diameter was 5-10 $\mathrm{nm}$ (Fig. 2c). The high-resolution TEM image of $\mathrm{LaPO}_{4}$ indicated that the spacing of the sample between two adjacent horizontal and vertical lattice planes is $3.00 \AA$ and $3.17 \AA$ (Fig. 2d), close to the $d_{200}$ (3.0662 ̊) and $d_{111}(3.1057 \AA)$, respectively.

Comparative experiments were carried out to investigate the effects of the ligand citrate on the structure and morphology of the products. The citrate concentration was changed from 0.0 to $3.0 \mathrm{mmol}$. Fig. 3 showed the XRD pattern of the products synthesized with different citrate concentration. XRD pattern of the product prepared without citrate was shown in Fig. 3a. All the diffraction peaks agree well with hexagonal phase $\mathrm{LaPO}_{4}$ (JCPDS 75-1881). When the citrate concentration was $0.2 \mathrm{mmol}$, the monoclinic phase appeared but the majority phase was hexagonal phase (Fig. 3b). When the citrate concentration was $0.5 \mathrm{mmol}$, the diffraction intensity of monoclinic phase enhanced (Fig. 3c). While citrate concentration was reaching $0.8 \mathrm{mmol}$, all diffraction peaks of the product fit well with the diffraction peaks of pure monoclinic phase $\mathrm{LaPO}_{4}$ (JCPDS 320493), and no hexagonal phase was observed (Fig. 3d). However, when citrate concentration increased to $0.9 \mathrm{mmol}$, the diffraction peak of the hexagonal phase appeared again (Fig. 3e). With the citrate concentration increasing to $1.0 \mathrm{mmol}$, the diffraction intensity of the hexagonal phase enhanced gradually (Fig. 3f). When the citrate concentration was reaching to $3.0 \mathrm{mmol}$, the products transform into a hexagonal phase again (Fig. $3 \mathrm{~g}$ and $\mathrm{h}$ ).

The above comparative experiments showed that the citrateinduced the phase transformation of $\mathrm{LaPO}_{4}$. The corresponding SEM images were showed in Fig. 4. Fig. 4a indicated the image of product prepared without citrate. The product was composed

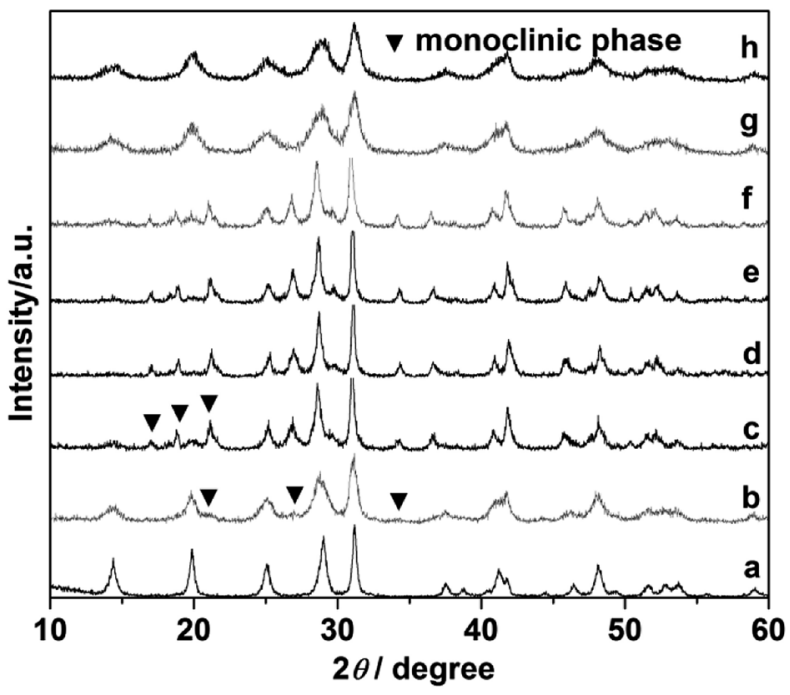

Fig. 3 XRD pattern of the $\mathrm{LaPO}_{4}$ prepared with different citrate concentration: (a) 0, (b) 0.2, (c) 0.5, (d) 0.8, (e) 0.9, (f) 1.0, (g) 2.0, (h) $3.0 \mathrm{mmol}$.

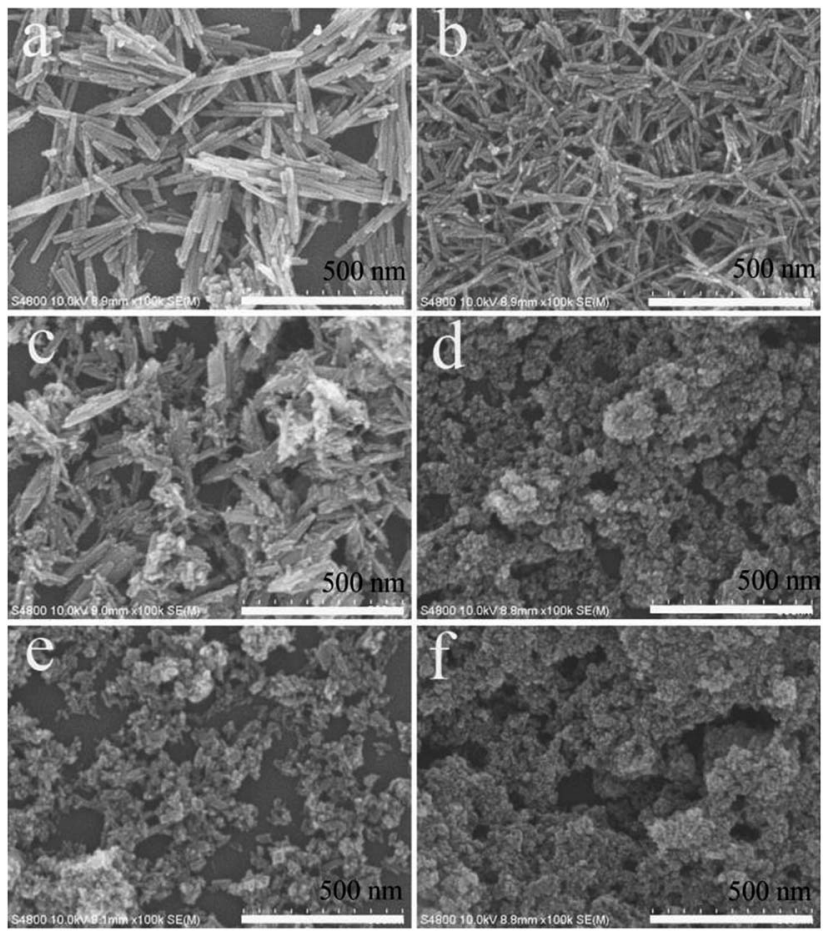

Fig. 4 SEM images of the $\mathrm{LaPO}_{4}$ nanostructures prepared with different citrate concentration: (a) 0 , (b) 0.2, (c) 0.5, (d) 0.8, (e) 1.0, (f) $3.0 \mathrm{mmol}$.

with nanowires with a diameter about $20-30 \mathrm{~nm}$ and length of 300-500 nm. A large number of uniform nanorods with a length of $80-100 \mathrm{~nm}$ and a diameter of $10-20 \mathrm{~nm}$ were observed in the product, when the citrate concentration was $0.2 \mathrm{mmol}$ (Fig. $4 \mathrm{~b}$ ). While the citrate concentration was changed from 0.5 to $1.0 \mathrm{mmol}$, the morphology of the products was rod-like nanoparticles and nanoparticles (Fig. 4c-e). As the citrate concentration increased to $3.0 \mathrm{mmol}$, the product was composed of nanorods with a diameter of 5-10 $\mathrm{nm}$ and length about 20$30 \mathrm{~nm}$ (Fig. 4f).

In our reaction system, the monoclinic phase $\mathrm{LaPO}_{4}$ could be successfully prepared with citrate-induced at low temperature. When the citrate concentration was $0.8 \mathrm{mmol}$, the monoclinic phase $\mathrm{LaPO}_{4}$ was obtained. Citrate served as ligand and chelating agent of the $\mathrm{La}^{3+}$ ions, it might result in the growth of initial monoclinic $\mathrm{LaPO}_{4}$ particles. ${ }^{21}$ However, when the citrate concentration was increased to $0.9 \mathrm{mmol}$, the mixed hexagonal and monoclinic phase was obtained. The citrate concentration was further increased to $1.5 \mathrm{mmol}$, the hexagonal phase $\mathrm{LaPO}_{4}$ was formed, the phase transformation cannot complete. In addition, we also investigated the effect of citrate concentration on the phase transformation of $\mathrm{CePO}_{4}$. Firstly, we found that the hexagonal phase $\mathrm{CePO}_{4}$ was prepared when the reaction temperature was $100{ }^{\circ} \mathrm{C}$ and the citrate concentration varying from $0.0 \mathrm{mmol}$ to $3.0 \mathrm{mmol}$ (Fig. S1 $\dagger$ ). Subsequently, when the reaction temperature was increased to $150{ }^{\circ} \mathrm{C}$ and the citrate concentration was increased from $0.0 \mathrm{mmol}$ to $3.0 \mathrm{mmol}$, XRD patterns of the $\mathrm{CePO}_{4}$ was showed in Fig. 5. If the $\mathrm{CePO}_{4}$ was prepared without citrate, all the diffraction peaks would agree well with hexagonal $\mathrm{CePO}_{4}$ (JCPDS 34-1380). With the citrate concentration increasing to 


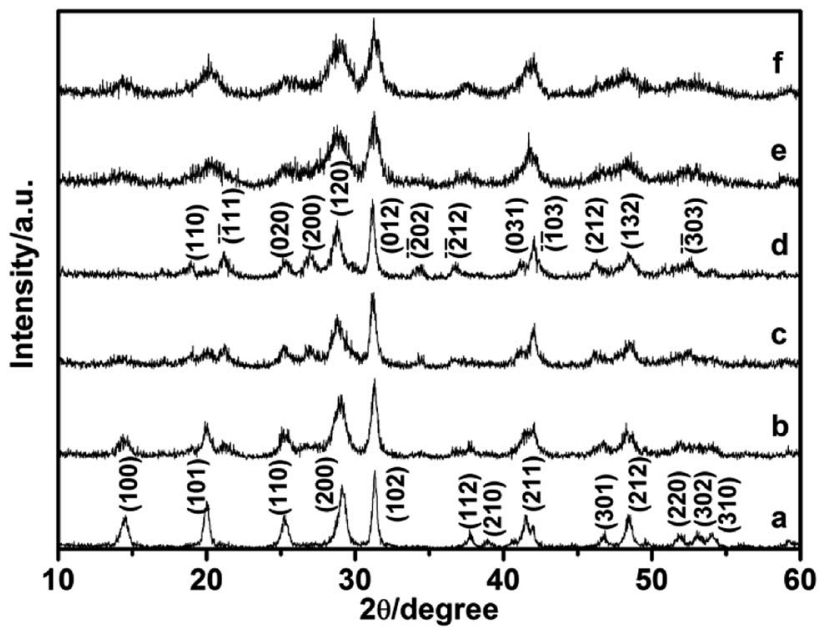

Fig. 5 XRD pattern of the $\mathrm{CePO}_{4}$ prepared with different citrate concentration: (a) 0, (b) 0.2, (c) 1.0, (d) 1.2, (e) 2.0, (f) $3.0 \mathrm{mmol}$.

$0.2 \mathrm{mmol}$, the mixed hexagonal and monoclinic phase appeared (Fig. 5b). Fig. 5c showed that the diffraction of monoclinic phase enhanced gradually while citrate was $1.0 \mathrm{mmol}$. Furthermore, the citrate concentration increased to $1.2 \mathrm{mmol}$, all diffraction peaks can be indexed to monoclinic $\mathrm{CePO}_{4}$ (JCPDS 32-0199), with no hexagonal phases being observed (Fig. $5 \mathrm{~d}$ ). When citrate increased to $2.0 \mathrm{mmol}$, diffraction peaks of the mixed hexagonal and monoclinic phase appeared again (Fig. 5e). Up to $3.0 \mathrm{mmol}$ citrate concentration, the product completely transformed into pure hexagonal phase (Fig. 5f). The experimental result showed that the monoclinic phase $\mathrm{CePO}_{4}$ prepared with $1.2 \mathrm{mmol}$ citrate-induced at $150{ }^{\circ} \mathrm{C}$. However, if the citrate concentration was higher than $1.2 \mathrm{mmol}$, the monoclinic phase $\mathrm{CePO}_{4}$ cannot be obtained. It further confirms that the citrate concentration have remarkable impact on $\mathrm{CePO}_{4}$ transformation. While the citrate concentration was increased, it was possible to increase $\mathrm{pH}$ value of the solution. The phase transformation will be influenced by $\mathrm{pH}$ value of reaction solution. Therefore, $\mathrm{pH}$ values of the reaction solution were further measured at different reaction stages times (Table 1). It can be seen that $\mathrm{pH}$ values of reaction solution increased with increasing the citrate concentration. The reaction environment of $\mathrm{La}^{3+}$ ions and $\mathrm{PO}_{4}{ }^{3-}$ began changing when the citrate concentration was higher. When the citrate concentration was $0.8 \mathrm{mmol}, \mathrm{pH}$
(2) value was 1.69 , the monoclinic phase $\mathrm{LaPO}_{4}$ was synthesized by a citrate-induced at $100{ }^{\circ} \mathrm{C}$. Interestingly, as the citrate concentration was $0.9 \mathrm{mmol}, \mathrm{pH}(2)$ value was 1.88 , the mixed hexagonal and monoclinic phase $\mathrm{LaPO}_{4}$ could be obtained. Then the pure hexagonal phase was synthesized when the citrate concentration was $1.5 \mathrm{mmol}$ and $\mathrm{pH}(2)$ value was 3.57. Therefore, $\mathrm{pH}$ values of reaction solution increases with increasing the citrate concentration, which disturb the citrate-induced function, and the phase transformation cannot complete.

To further understand the $\mathrm{pH}$ values influence on the phase transformation of the products, the comparative experiments were employed using ammonia or nitric acid to adjust the $\mathrm{pH}$ value without citrate-induced. If the products prepared without citrate-induced, the hexagonal phase $\mathrm{LaPO}_{4}$ could be obtained at $100{ }^{\circ} \mathrm{C}$ (Fig. S2a $\dagger$ ), and the mixed hexagonal and monoclinic phase was prepared at $150^{\circ} \mathrm{C}$ (Fig. S2b $\dagger$ ). At $170{ }^{\circ} \mathrm{C}$, the product was monoclinic phase (Fig. S2c $\dagger$ ). Subsequently, when the reaction temperature was $100{ }^{\circ} \mathrm{C}$ and $170{ }^{\circ} \mathrm{C}$, the products prepared with hydrothermal route using $0.1 \mathrm{~mol} \mathrm{dm}^{-3} \mathrm{H}_{3} \mathrm{PO}_{4}$ and $\mathrm{La}\left(\mathrm{NO}_{3}\right)_{3}$ as reactant using ammonia or nitric acid to adjust the $\mathrm{pH}$ value of the reaction solution. Fig. $\mathrm{S} 3$ and $\mathrm{S} 4 \dagger$ showed XRD pattern of $\mathrm{LaPO}_{4}$ obtained at $100{ }^{\circ} \mathrm{C}$ and $170{ }^{\circ} \mathrm{C}$ with different $\mathrm{pH}$ value. When the reaction temperature was $100^{\circ} \mathrm{C}$, and $\mathrm{pH}$ values were 1.0, 5.0, 7.0, and 9.0, all diffraction peaks of the products coincided with hexagonal phase (Fig. S3†). With the reaction temperature increasing to $170^{\circ} \mathrm{C}$ and $\mathrm{pH}=1.0$, the monoclinic phase $\mathrm{LaPO}_{4}$ was synthesized (Fig. S4a $\dagger$ ). However, if the $\mathrm{pH}$ values of reaction system were greater than 2.0, all products would exhibit hexagonal phase structure (Fig. S4b-e †). The monoclinic phase $\mathrm{LaPO}_{4}$ could be synthesized without citrate-induced at $170{ }^{\circ} \mathrm{C}$, but $\mathrm{pH}$ value of the reaction system should be smaller than 2.0. The $\mathrm{pH}$ value would be higher than 1.69 when the concentration of citrate was greater than $0.8 \mathrm{mmol}$. Furthermore, We found that the citrate-induced function would become unavailable under this condition. That is, the pure monoclinic phase $\mathrm{LaPO}_{4}$ cannot be obtained and the hexagonal phase $\mathrm{LaPO}_{4}$ was synthesized.

Therefore, we suggest a possible formation mechanism of the influence of citrate on phase transformation based on the above results (Fig. 6). First, when the citrate concentration increased to $0.8 \mathrm{mmol}$, the hexagonal phase $\mathrm{LaPO}_{4}$ transformed into monoclinic phase. During the process of synthesis, $\mathrm{pH}$

Table $1 \mathrm{pH}$ values of the reaction system, when the $\mathrm{LaPO}_{4}$ synthesized with different concentration of citrate ${ }^{a}$

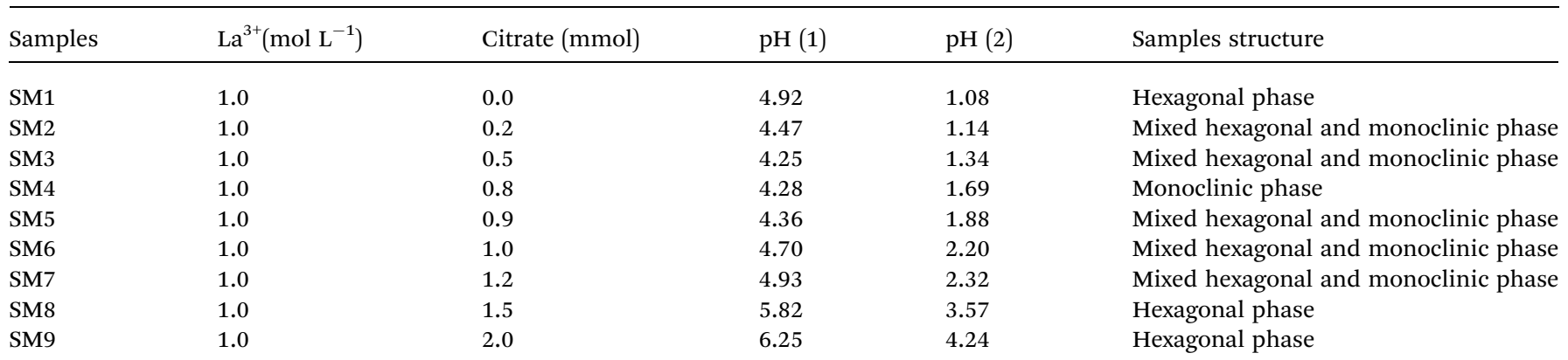

${ }^{a} \mathrm{pH}(1)$ was the $\mathrm{pH}$ value of the reaction solution after citrate added to $\mathrm{La}\left(\mathrm{NO}_{3}\right)_{3}$ solution, and $\mathrm{pH}(2)$ was the $\mathrm{pH}$ value of the reaction solution after added $\mathrm{H}_{3} \mathrm{PO}_{4}$. 


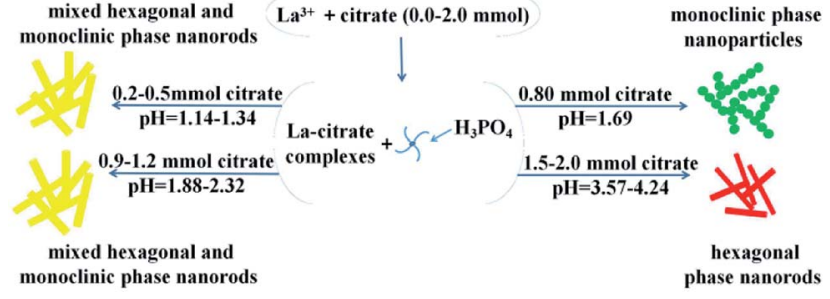

Fig. 6 The crystal growth mechanism of the $\mathrm{LaPO}_{4}$ nanostructures with hexagonal and monoclinic phase.

value was 1.69. The citrate possesses three carboxylic functional groups, which chelated with $\mathrm{RE}^{3+}$ ions to form RE-citrate complex. Then RE-citrate complex reacted with $\mathrm{PO}_{4}{ }^{3-}$ to produce $\mathrm{REPO}_{4}$ via the substitution reaction after adding the phosphorus source $\mathrm{H}_{3} \mathrm{PO}_{4}$. In the reaction procedure, the presence of citrate complexes caused the $\mathrm{RE}^{3+}$ to be slowly released. ${ }^{21}$ It is quite possible that the substituted citrate ions are adsorbed onto the surface of the initially formed tiny hexagonal $\mathrm{REPO}_{4}$ nanoparticles around $\mathrm{RE}^{3+}$ cation, which might result in the growth of initial monoclinic $\mathrm{REPO}_{4}$ particles. $^{20}$ Second, if the citrate concentration increasing higher than $0.8(\mathrm{pH}>1.69)$, the condition would not conducive to the preferential growth of monoclinic phase nanoparticles. Third, with the citrate concentration increased from $0.9 \mathrm{mmol}$ to $1.2 \mathrm{mmol}(\mathrm{pH}=1.88-2.32)$, the mixed hexagonal phase and monoclinic phase $\mathrm{LaPO}_{4}$ was obtained. Finally, when the citrate concentration was higher than $1.5 \mathrm{mmol}(\mathrm{pH}>3.57)$, the hexagonal phase $\mathrm{LaPO}_{4}$ was synthesized but the monoclinic phase $\mathrm{LaPO}_{4}$ could not be obtained.

\subsection{Photoluminescence properties}

$5 \% \mathrm{Eu}^{3+}$-doped $\mathrm{LaPO}_{4}$ with different phase prepared by citrateinduced. We found that the addition of $5 \% \mathrm{Eu}^{3+}$ to the raw $\mathrm{La}^{3+}$ solution did not affect the crystalline structure (Fig. S5†). EDX analysis clearly indicated the presence of specific dopant $\mathrm{Eu}^{3+}$ ion in the synthesized product (Fig. S6 $\dagger$ ). It can be confirmed by the content of the elements shown in EDX that the synthesized product was $\mathrm{La}_{0.95} \mathrm{PO}_{4}: \mathrm{Eu}_{0.05}$.

The photoluminescence (PL) spectra were measured at room temperature. The excitation peak of the products centered at 393 nm (Fig. S7†). Fig. 7 exhibits the emission spectra of $\mathrm{LaPO}_{4}$ :Eu with different phase under excitation at $393 \mathrm{~nm}$. The emission spectra exhibits four characteristic emission lines, which were attributed to the ${ }^{5} \mathrm{D}_{0} \rightarrow{ }^{7} \mathrm{~F}_{\mathrm{J}}(J=1-4)$ transitions of $\mathrm{Eu}^{3+}$. The magnetic dipole transition $\left({ }^{5} \mathrm{D}_{0} \rightarrow{ }^{7} \mathrm{~F}_{1}\right)$ occupied a dominate position in as-synthesized hexagonal phase (Fig. 7a and c). It is known that while the $\mathrm{Eu}^{3+}$ is in the symmetry center of the lattice, the electric dipole transition is forbidden, the intensity of the ${ }^{5} \mathrm{D}_{0} \rightarrow{ }^{7} \mathrm{~F}_{2}$ transition band in the emission spectra is weak, the intensity of the ${ }^{5} \mathrm{D}_{0} \rightarrow{ }^{7} \mathrm{~F}_{1}$ transition band is strong. ${ }^{26,27}$ In addition, the emission peaks split to multi-peaks. It was due to that the perturbation of the crystal field and the change of the local site symmetry, the degeneracy of ${ }^{7} \mathrm{~F}_{\mathrm{J}}(J=1-4)$ energy level was resolved. ${ }^{28}$ However, the monoclinic phase prepared with citrate-induced has higher intensity at the

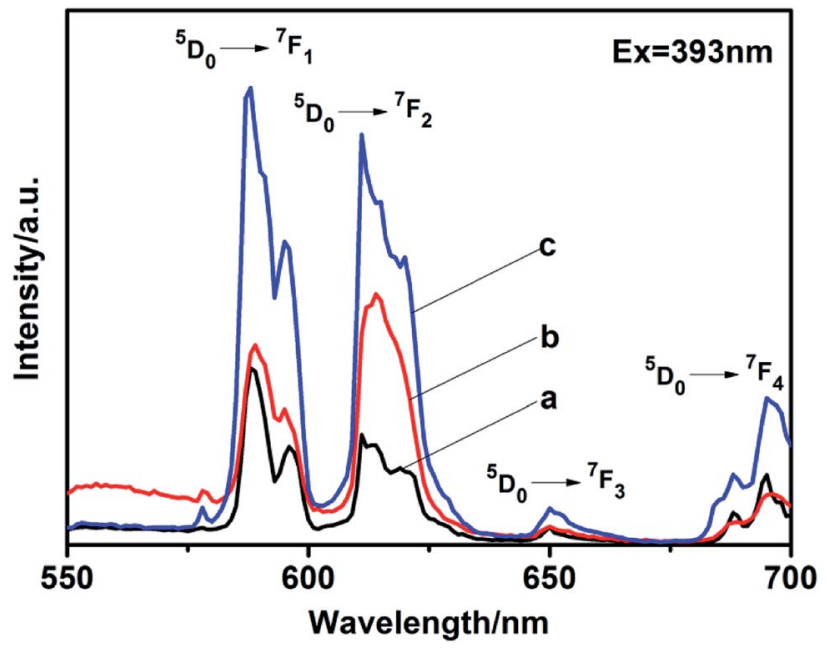

Fig. 7 Emission spectra of $\mathrm{LaPO}_{4}$ :Eu with different phase: (a) hexagonal phase prepared without citrate, (b) monoclinic phase prepared with citrate-induced, (c) hexagonal phase prepared with citrateinduced.

electric dipole transition $\left({ }^{5} \mathrm{D}_{0} \rightarrow{ }^{7} \mathrm{~F}_{2}\right)$ than that at the magnetic dipole transition $\left({ }^{5} \mathrm{D}_{0} \rightarrow{ }^{7} \mathrm{~F}_{1}\right)$, which means $\mathrm{Eu}^{3+}$ is in a site with no inversion center (Fig. 7b). ${ }^{29-31}$ While the absolute quantum yield of the monoclinic phase $\mathrm{LaPO}_{4}$ :Eu is $10.71 \%$. Moreover, the emission intensity of the hexagonal phase prepared with citrate-induced is stronger than that of the hexagonal phase prepared without citrate. The absolute quantum yield of the hexagonal phase $\mathrm{LaPO}_{4}: \mathrm{Eu}$ prepared with citrate-induced is $14.73 \%$, while the hexagonal phase $\mathrm{LaPO}_{4}$ :Eu prepared without citrate is $9.24 \%$. The size, morphology and structure maybe also influenced the photoluminescence intensities. ${ }^{32-35}$ The photoluminescence fitting curves of $\mathrm{LaPO}_{4}$ :Eu with different phase were also recorded, as shown in Fig. S8. $\dagger$ The calculated average lifetime $(\tau)$ was $0.82 \mathrm{~ms}$ for the monoclinic phase $\mathrm{LaPO}_{4}: \mathrm{Eu}$ prepared with citrate-induced. Furthermore, the calculated average lifetimes $(\tau)$ were $1.83 \mathrm{~ms}$ and $1.51 \mathrm{~ms}$ for the hexagonal phase $\mathrm{LaPO}_{4}: \mathrm{Eu}$ prepared with citrate-induced and without citrate, respectively.

\section{Conclusions}

In this paper, we have developed a low temperature and citrateinduced hydrothermal route for the crystal growth of monoclinic phase $\mathrm{LaPO}_{4}$ and $\mathrm{LaPO}_{4}$ :Eu nanostructures. The conclusions of the research were as follows: (1) when the monoclinic phase $\mathrm{LaPO}_{4}$ was synthesized through hydrothermal route at $170{ }^{\circ} \mathrm{C}$, the $\mathrm{pH}$ value of reaction system should be less than or equal to 1.0. (2) The monoclinic phase $\mathrm{LaPO}_{4}$ was controlled synthesized through citrate-induced at $100{ }^{\circ} \mathrm{C}$, when the concentration of citrate was $0.8 \mathrm{mmol}$. High concentration of citrate would result in the $\mathrm{pH}$ value of the reaction system higher than 1.88, which cannot synthesize the monoclinic phase $\mathrm{LaPO}_{4}$ with citrate-induced. The hexagonal phase $\mathrm{LaPO}_{4}$ was obtained. (3) Significantly, the photoluminescence properties demonstrate that the electric dipole transition $\left({ }^{5} \mathrm{D}_{0} \rightarrow{ }^{7} \mathrm{~F}_{2}\right)$ is stronger than the magnetic dipole transition $\left({ }^{5} \mathrm{D}_{0} \rightarrow{ }^{7} \mathrm{~F}_{1}\right)$ for 
the monoclinic phase $\mathrm{LaPO}_{4}$ :Eu prepared with citrate-induced. The hexagonal phase $\mathrm{LaPO}_{4}: \mathrm{Eu}$ with citrate-induced have stronger emission intensity than the hexagonal phase $\mathrm{LaPO}_{4}: \mathrm{Eu}$ without citrate-induced. Due to low temperature synthesis method of this system and the effective control over the phase transformation it has achieved, we suppose this study may have broad application prospects in exploring crystal growth process.

\section{Conflicts of interest}

There are no conflicts to declare.

\section{Acknowledgements}

This work was supported by the National Natural Science Foundations of China (21766021); the Major projects of Natural Science Foundations of Inner Mongolia Science Foundation (2015ZD01); and the Natural Science Foundations of Inner Mongolia Science Foundation (2015MS0502).

\section{Notes and references}

1 S. Heer, O. Lehmann, M. Haase and H. U. Güdel, Angew. Chem., Int. Ed., 2003, 42, 3179-3182.

2 A. I. Becerro, S. Rodríguez-Liviano, A. J. Fernández-Carrión and M. Ocaña, Cryst. Growth Des., 2013, 13, 526-535.

3 G. F. Ju, Y. H. Hu, L. Chen, X. J. Wang, Z. F. Mu, H. Y. Wu and F. W. Kang, J. Alloys Compd., 2011, 509, 5655-5659.

4 K. Park and M. H. Heo, J. Alloys Compd., 2011, 509, 91119115.

5 S. H Lee, K. Teshima, S. Mori, M. Endo and S. J. Oishi, Cryst. Growth Des., 2010, 10, 1693-1698.

6 B. Sun and H. Sirringhaus, Nano Lett., 2005, 5, 2408-2413.

7 M. F. Dumont, C. Baligand, Y. C. Li, E. S. Knowles, M. W. Meisel, G. A. Walter and D. R. Talham, Bioconjugate Chem., 2012, 23, 951-957.

8 R. X. Yan, X. M. Sun, X. Wang, Q. Peng and Y. D. Li, Chem.Eur. J., 2005, 11, 2183-2195.

9 Y. P. Fang, A. W. Xu, R. Q. Song, H. X. Zhang, L. P. You, J. C. Yu and H. Q. Liu, J. Am. Chem. Soc., 2003, 125, 1602516034.

10 K. S. Gavrichev, M. A. Ryumin, A. V. Tyurin, A. V. Khoroshilov, L. P. Mezentseva, A. V. Osipov, V. L. Ugolkov and V. V. Gusarov, J. Therm. Anal. Calorim., 2010, 102, 809-811.

11 Y. J. Zhang and H. M. Guan, J. Cryst. Growth, 2003, 256, 156161.

12 S. Z. Lin, X. T. Dong, R. K. Jia and Y. L. Yuan, J. Mater. Sci.: Mater. Electron., 2010, 21, 38-44.

13 C. R. Kesavulu, C. Basavapoornima, C. S. Dwaraka Viswanath and C. K. Jayasankar, J. Lumin., 2016, 171, 51-57.
14 K. Riwotzki, H. Meyssamy, A. Kornowski and M. Haase, J. Phys. Chem. B, 2000, 104, 2824-2828.

15 T. Huang, S. R. Shieh, A. Akhmetov, X. Liu, C. M. Lin and J. S. Lee, Phys. Rev. B: Condens. Matter Mater. Phys., 2010, 81, 214117.

16 D. Errandonea, J. Pellicer-Porres, F. J. Manjón, A. Segura, Ch. Ferrer-Roca, R. S. Kumar, O. Tschauner, P. RodríguezHernández, J. López-Solano, S. Radescu, A. Mujica, A. Muñoz and G. Aquilanti, Phys. Rev. B: Condens. Matter Mater. Phys., 2005, 72, 174106.

17 J. M. Heuser, R. I. Palomares, J. D. Bauer, M. J. Lozano Rodriguez, J. Cooper, M. Lang, A. C. Scheinost, H. Schlenz, B. Winkler, D. Bosbach, S. Neumeier and G. Deissmann, J. Eur. Ceram. Soc., 2018, 38, 4070-4081.

18 M. A. Musselman, T. M. Wilkinson, B. Haberl and C. E. Packard, J. Am. Ceram. Soc., 2018, 101, 2562-2570.

19 F. Luo, C. J. Jia, W. Song, L. P. You and C. H. Yan, Cryst. Growth Des., 2005, 5, 137-142.

20 J. R. Bao, R. B. Yu, J. Y. Zhang, D. Wang, J. X. Deng, J. Chen and X. R. Xing, Scr. Mater., 2010, 62, 133-136.

21 N. O. Nuñez, S. R. Liviano and M. Ocaña, J. Colloid Interface Sci., 2010, 349, 484-491.

22 J. Q. Hu, Q. Chen, Z. X. Xie, G. B. Han, R. H. Wang, B. Ren, Y. Zhang, Z. L. Yang and Z. Q. Tian, Adv. Funct. Mater., 2004, 14, 183-189.

23 X. H. Ji, X. N. Song, J. Li, Y. B. Bai, W. S. Yang and X. G. Peng, J. Am. Chem. Soc., 2007, 129, 13939-13948.

24 W. H. Di, M. G. Willinger, R. A. S. Ferreira, X. G. Ren, S. Z. Lu and N. Pinna, J. Phys. Chem. C, 2008, 112, 18815-18820.

25 L. Zhang, L. L. Fu, X. X. Yang, Z. L. Fu, X. D. Qi and Z. J. Wu, J. Mater. Chem. C, 2014, 2, 9149-9158.

26 Y. G. Yang, Mater. Sci. Eng., B, 2013, 178, 807-810.

27 C. Zollfrank, H. Scheel, S. Brungs and P. Greil, Cryst. Growth Des., 2008, 8, 766-770.

28 Y. H. Zheng, H. P. You, G. Jia, K. Liu, Y. H. Song, M. Yang and H. J. Zhang, Cryst. Growth Des., 2009, 9, 5101-5107.

29 X. Y. Huang, H. Guo and B. Li, J. Alloys Compd., 2017, 720, 29-38.

30 X. Y. Huang, B. Li, H. Guo and D. Q. Chen, Dyes Pigm., 2017, 143, 86-94.

31 P. Du, X. Y. Huang and J. S. Yu, Chem. Eng. J., 2018, 337, 91100.

32 M. Wang, Q. L. Huang, J. M. Hong, X. T. Chen and Z. L. Xue, Cryst. Growth Des., 2006, 6, 1972-1974.

33 J. Geng, Y. N. Lv, D. J. Lu and J. J. Zhu, Nanotechnology, 2006, 17, 2614-2620.

34 X. C. Wu, Y. R. Tao, C. Y. Song, C. J. Mao, L. Dong and J. J. Zhu, J. Phys. Chem. B, 2006, 110, 15791-15796.

35 L. M. Chen, Y. N. Liu and K. L. Huang, Mater. Res. Bull., 2006, 41, 158-166. 